\title{
EFEITOS DAS REGRAS FISCAIS E TRANSFERÊNCIAS NA ALOCAÇÃO DOS GASTOS PÚBLICOS NOS MUNICÍPIOS PARANAENSES: 2002-2011
}

\section{EFFECTS OF FISCAL RULES AND TRANSFERENCES IN ALLOCATION OF PUBLIC EXPENSES IN PARANÁ MUNICIPALITIES: 2002-2011}

\section{Resumo}

\author{
Carin Caroline Deda ${ }^{1}$ \\ Fernando Motta Correia ${ }^{2}$ \\ Samira Kauchakje ${ }^{3}$
}

Este artigo tem como objetivo investigar os possíveis impactos da Lei de Responsabilidade Fiscal (LRF) e das transferências intergovernamentais, representadas pelo Fundo de Participação dos Municípios (FPM), na alocação dos gastos com investimento e com pessoal nos municípios paranaenses. Especificamente, buscar-se-á observar se e como essas regras para alocação de recursos afetaram o comportamento dos decisores governamentais. Para tanto, parte-se do entendimento que a LRF e FPM são normas de âmbito nacional que orientam o comportamento de gestores públicos subnacionais. Este estudo utiliza uma metodologia econométrica baseando-se na estimação de um modelo com dados em painel abordando o período de 2002 a 2011. Os resultados indicam que a dependência das transferências promove um impacto positivo na alocação dos gastos com investimento em detrimento dos gastos com pessoal, entretanto a LRF suscita um efeito contrário na medida em que estimula os entes federativos a alocarem uma maior parcela dos seus gastos com pessoal e tal fato pode vir acompanhado de redução de gastos com investimentos.

Palavras-chave: Lei de Responsabilidade Fiscal. Transferências intergovernamentais. Gastos públicos. Municípios paranaenses. Dados em painel.

\begin{abstract}
This objective of this article is to investigate the possible impacts of the Fiscal Responsibility Law (FRL) and the intergovernmental transferences in the representation of the Municipalities Participation Fund (MPF) in the allocation of investment and staff expenses in the Paraná municipalities. Specifically, it will seek to observe if and how these rules for allocation of resources affected the behavior of governmental decision makers. Therefore, assumes that the FRL and the MPF are national rules governing the behavior of public managers of subnational governments. This study uses an econometric methodology based on the estimation of a panel data model, covering the period 2002 to 2011. The results indicate that the dependence of transfers promotes a positive impact on the allocation of investment expenses in detriment to the staff expenses, however the FRL has created an opposite effect in so far encourages the federative entities to allocate a greater share of their staff expenses and this fact may be accompanied by reduced spending on investment.

Keywords: Fiscal Responsibility Law. Intergovernmental transferences. Public expenses. Paraná municipalities. Panel data.

\footnotetext{
1 Economista. Mestranda do Programa de Pós-Graduação em Gestão Urbana da PUCPR. E-mail: caroline.deda@yahoo.com.br

${ }^{2}$ Economista. Professor do Programa de Pós-Graduação em Desenvolvimento Econômico da UFPR. E-mail: fmottabr@yahoo.com.br

${ }^{3}$ Cientista Política. Professora no Programa de Pós-Graduação em Gestão Urbana da PUCPR. Professora colaboradora no Programa de Pós-Graduação em Ciência Política da UFPR. E-mail: skauchakje@gmail.com
} 


\section{INTRODUÇÃO ${ }^{4}$}

A Constituição Federal de 1988 favoreceu o processo de descentralização fiscal da esfera federal para as estaduais e municipais, tendo em vista uma maior eficiência dos gastos públicos, o que proporcionou aos municípios brasileiros uma maior autonomia financeira e responsabilidade fiscal. Em função das diversidades e características existentes nos municípios, observa-se uma forte desigualdade inter-regional. Para minimizar esse problema, um dos mecanismos institucionais de equilíbrio das finanças públicas são as transferências intergovernamentais. No regime federativo brasileiro essas transferências têm o intuito de promover o equilíbrio socioeconômico corrigindo as disparidades existentes e visando a eficiência do gasto público e a equalização das receitas.

Nesse contexto, um fator que merece atenção é a Lei de Responsabilidade Fiscal - LRF instituída em 2000, cujo principal objetivo é promover a transparência na gestão fiscal e o controle dos gastos públicos. A LRF tem grande importância no cenário econômico, uma vez que, pressupõe a ação planejada e transparente da administração pública mediante o cumprimento de metas fiscais, mecanismos de controle das finanças públicas e exigência de apresentação de relatórios de acompanhamento. Além disso, em âmbito geral, a LRF estabeleceu um limite superior de $60 \%$ da receita corrente líquida para gastos com pessoal nos estados e municípios e fixou limite de endividamento em uma relação de 1,2 entre a dívida consolidada líquida e a receita corrente. Conforme explicitado pelos autores, destaca-se a fixação de limites para despesas com pessoal:

A Lei de Responsabilidade Fiscal obriga os governantes, em todas as esferas, a instituírem e a arrecadarem todos os tributos de competência própria e dificulta a renúncia de receita, bem como estabelece parâmetros e limites para as despesas, dentre as quais se destaca a despesa com pessoal (VELOSO e TEIXEIRA, 2007, v. 28, p. 451).

É importante ressaltar que a ação eficiente do setor público necessita de um direcionamento adequado dos recursos, bem como uma distribuição dos bens e serviços com qualidade. Nessa perspectiva, pressupõe-se que tanto as transferências intergovernamentais quanto a LRF direcionam os gestores públicos ao atendimento das demandas públicas. Porém, embora as transferências promovam uma melhor eficiência do gasto público, em que os gestores alocam os recursos visando um melhor desempenho municipal, a LRF pode ocasionar um efeito contrário na medida em que estimula os entes federativos a alocarem uma maior parcela dos seus gastos com pessoal e tal fato pode vir acompanhado de redução de gastos com investimentos.

\footnotetext{
${ }^{4}$ Este artigo é baseado nos resultados da pesquisa do autor (AUTOR. Curitiba, 2014).
} 
Estudos como o de Fioravante et al. (2006) apontam a eficácia da LRF no sentido da redução dos déficits municipais. Todavia a imposição de um limite superior de $60 \%$ da despesa com pessoal como proporção da receita estimulou o aumento desse gasto na maioria dos entes federativos que apresentavam despesas inferiores a esse teto.

Também é importante ressaltar que mediante a forma de como são alocadas essas despesas, a administração pública pode interferir promovendo efeitos representativos nas conjunturas municipais, uma vez que, as decisões de despesas com investimento e com pessoal podem afetar a incidência destes gastos sobre a economia.

Santolin et al. (2009) realizaram um estudo buscando identificar os possíveis impactos da LRF no comportamento das despesas dos municípios de Minas Gerais. Para tanto, os autores utilizaram um modelo econométrico a fim de analisar se os municípios mineiros têm aumentado suas despesas de pessoal em razão da queda das despesas de investimento, bem como, se a elevação das despesas com pessoal não se deve ao decréscimo das despesas com investimento, analisando cenários anteriores e posteriores da LRF. Os autores concluem que a junção de elementos pós implementação da LRF desencadeou um processo de convergência de gastos com pessoal e austeridade das despesas de investimento nos municípios mineiros.

É possível observar que as regras fiscais podem causar distorções no equilíbrio federativo afetando políticas que tenham o objetivo de promover equiparação regional, como é o caso das transferências intergovernamentais. Sendo assim, infere-se a existência de um duelo entre a LRF e o FPM, uma vez que, esta interação induz os municípios a realizarem determinadas alocações de despesas que acabam punindo os investimentos, pois a LRF está sendo um limitante para a alocação eficiente dos gastos municipais, uma vez que, impõe limites de despesas que tratam igualmente os desiguais e não produz regras bem definidas para a rubrica investimento.

As instituições são padrões regularizados de interação entre agentes que esperam continuar interagindo sobre as regras e normas formais e informais incorporadas nesses padrões, e as regras estabelecidas pelas instituições influenciam a conduta dos agentes que tomam decisões conforme a probabilidade de obterem resultados favoráveis (O'Donnell, 1991). De acordo com North (1990), a existência de incerteza no ambiente econômico e social dos agentes e o objetivo de superar os custos de transação leva ao surgimento de instituições definidas como um conjunto de restrições que podem ser formais e informais, sendo as restrições formais, leis, regras, constituições, etc, e as informais as imposições de comportamento, códigos de conduta, etc. 
A LRF é uma regra que orienta comportamentos, e parte-se do pressuposto de que os gestores públicos, a partir da implementação desta Lei, tendem a adotar um comportamento padrão ajustando as despesas com pessoal aos limites impostos pela LRF. Decisões de gasto com pessoal e com investimento podem ser um instrumento de barganha política, uma vez que são utilizadas como indicador de aprovação populacional, o que pode acarretar a permanência ou não do partido que detém o poder local nas eleições (Santolin et al. 2009). Os agentes atuam de acordo com o grau de agregação que é mais eficaz eles agirem, visando a obtenção de resultados favoráveis (O'Donnell, 1991). Diante disso, a rubrica investimento pode ser prejudicada, uma vez que, ao contrário da rubrica de gastos com pessoal, não há um enquadramento tão rígido desta despesa junto à LRF.

A razão para a realização desse artigo deve-se aos relevantes efeitos que podem ser ocasionados pelo modo com que são determinadas as despesas de investimento e de pessoal, a forma como os recursos são alocados pelos gestores públicos é um fator político-institucional que influencia nas conjunturas das organizações públicas. O aumento de gastos com pessoal pode causar uma consequente redução de gastos com investimentos impactando, no caso desta pesquisa, nas conjunturas municipais. Assim, o artigo tem como objetivo investigar os possíveis impactos da LRF e do FPM, na alocação dos gastos com investimento e com pessoal nos municípios paranaenses. Ou seja, busca-se responder as seguintes questões: A LRF está produzindo mudanças na alocação do gasto com investimento em detrimento do gasto com pessoal? Especificamente, buscar-se-á observar se e como o limite imposto por essa regra e paralelamente a dependência do FPM afetaram o comportamento dos gestores públicos. O universo de investigação da pesquisa são os municípios paranaenses por apresentarem uma heterogeneidade nas características dos municípios, o que pode refletir uma realidade nacional. A base teórica considerada é o institucionalismo da escolha racional que se propõe a explicar o comportamento de agentes no âmbito social e político, levando em conta que estes agem racionalmente sob constrangimentos institucionais, conforme North (1990), Tsebelis (1998), Baert (1997), entre outros. Para tanto, fezse um estudo por meio da utilização de um modelo econométrico com dados em painel visando identificar os impactos da LRF na alocação de despesa com investimento e com pessoal, bem como demais variáveis que influenciam a alocação de tais despesas para os municípios paranaenses no período de 2002 a 2011. Dado que a LRF foi implantada em 2000, os municípios brasileiros foram submetidos a uma disciplina fiscal, e os resultados decorrentes dessa nova configuração institucional podem ser observados a partir do ano 2000. 


\section{LEI DE RESPONSABILIDADE FISCAL}

A Lei Complementar no 101, chamada de Lei de Responsabilidade Fiscal - LRF, entrou em vigor em 04 de maio de 2000. Foi promulgada com o objetivo de promover o equilíbrio entre as despesas e as receitas dos entes federativos. Embora a LRF tenha sido implementada a fim de possibilitar maior controle das contas públicas, a motivação central de criação de tal regra fiscal reside na necessidade de se impor regras fiscais na esteira do tripé de política macroeconômica que se caracterizou no Brasil no fim da década de 90 e início dos anos 2000. A tentativa de induzir os gestores a terem maior responsabilidade para com as despesas, prevenindo riscos e corrigindo desvios capazes de afetar o equilíbrio das contas públicas foi o grande marco na tentativa de uma mudança cultural na gestão do orçamento público. É importante destacar a essência da LRF que se encontra em seu art. 1ㅇ, $\S 1$ ㅇ․

A responsabilidade na gestão fiscal pressupõe a ação planejada e transparente em que se previnem riscos e corrigem desvios capazes de afetar o equilíbrio das contas públicas, mediante o cumprimento de metas de resultados entre receitas e despesas e a obediência a limites e condições no que tange a renúncia de receita, geração de despesas com pessoal, de seguridade social e outras, dívidas consolidada e mobiliária, operações de crédito, inclusive por antecipação de receita, concessão de garantia e inscrição em Restos a Pagar (BRASIL. Lei no101, de 04 de maio de 2000).

Segundo Araujo e Moraes (2003), entre os mecanismos da LRF, destacam-se os limites aos gastos com pessoal e com endividamento. Em um âmbito geral, a LRF estabeleceu normas para as finanças públicas visando o seu aperfeiçoamento, exigindo controle do endividamento e das despesas, ampliou a obrigatoriedade de transparência, envolvendo planos, diretrizes orçamentárias e a elaboração dos orçamentos. Além disso, definiu metas fiscais anuais e a exigência de divulgação dos resultados obtidos por meio de apresentação de relatórios trimestrais de acompanhamento além de estabelecer mecanismos de controle das finanças públicas em anos eleitorais evitando a existência de ciclos políticos. Dentre as limitações de despesas impostas pela Lei, citam-se as principais:

1. Limite para a dívida pública, que para o caso dos municípios não deve ultrapassar 1,2 vezes a receita corrente líquida;

2. Limite para as operações de crédito;

3. Limite para as despesas com pessoal, que nos municípios não podem exceder $60 \%$ da receita corrente líquida;

4. Limite para a concessão de garantias; 
5. Limite de despesas com seguridade social;

6. Limite de gastos com educação e saúde.

Conforme descrevem Santolin et al. (2009), há mudança no comportamento dos gestores públicos a partir da instituição da LRF. As contas públicas apresentam uma situação melhor que nos períodos anteriores a sua promulgação. Todavia a LRF deve ser analisada criticamente, pois, embora tenha causado resultados positivos ela pode provocar distorções no equilíbrio federativo prejudicando a ação de políticas de equiparação regional:

Uma série de fatores demonstra que, embora a LRF tenha trazido novos conceitos, novas diretrizes e resultados positivos, ela pode provocar algumas distorções no equilíbrio federativo, prejudicando a execução de políticas que tenham o intuito de diminuir os desequilíbrios regionais (SANTOLIN et al. 2009, v. 39, p. 898).

Segundo Gerigk (2008), um dos objetivos principais da LRF é evitar os déficits nas contas públicas, impedindo que a administração assuma obrigações e encargos sem a correspondente fonte de receita ou redução da despesa, mantendo sob controle o nível de endividamento e assegurando o equilíbrio das finanças públicas.

Além disso, a LRF instituiu o conceito de Receita Corrente Líquida ( $R C L$ ) que corresponde ao somatório das receitas tributárias, de contribuições, patrimoniais, industriais, agropecuárias, de serviços, transferências correntes e outras receitas também correntes, diminuídas de algumas deduções que são diferenciadas para a União, estados e municípios. A RCL serve de parâmetro para a verificação de recursos, para o cumprimento de metas em geral e para o estabelecimento de limites para despesas com pessoal e endividamento, compatível com a responsabilidade fiscal exigida por essa Lei.

\section{Transferências intergovernamentais: a dependência do FPM no orçamento municipal}

A Constituição de 1988, favoreceu a descentralização e o federalismo fiscal no Brasil, diante disso, os municípios receberam maior autonomia e responsabilidade fiscal. Se por um lado os entes federativos passaram a ter maior responsabilidades na captura de suas fontes de recursos, por outro lado a descentralização fiscal advinda com a carta magna de 1988 transferiu maior responsabilidade na oferta de bens públicos para todos os entes federativos. Conforme Arretche (2002), as bases de autoridade dos governos locais foram alteradas profundamente a partir da 
descentralização fiscal, houve a expansão da autoridade local sobre os recursos fiscais, bem como maior autoridade tributária sobre impostos de significativa importância.

Como o Brasil é um país dotado de diferenças entre as jurisdições apresentando uma forte desigualdade territorial, existe no país uma série de recursos federais que visam manter o equilíbrio federativo (Souza, 2003). Neste cenário, destacam-se as transferências intergovernamentais que são uma forma de buscar maior eficiência do setor público no âmbito da implementação de políticas e serviços e representam um mecanismo de equilíbrio das finanças públicas. Elas são pertinentes nos regimes federativos onde a gestão fiscal objetiva principalmente tributar e efetuar o dispêndio com equidade e eficiência adequando a distribuição de recursos.

Por meio das transferências, o governo federal assume o papel de promover a redução das desigualdades inter-regionais, bem como a desigualdade de acesso da população a serviços públicos. No Brasil, em especial, em que há significativa desigualdade territorial ${ }^{5}$, a capacidade de os municípios proverem serviços públicos seria bastante desigual sem as transferências (Arretche, 2010). Outro fator que corrobora com a diminuição das desigualdades territoriais é a autoridade regulatória do governo central. Estados federativos que centralizam a autoridade regulatória da União operam no sentido da uniformidade criando mecanismos institucionais que promovem a redução das desigualdades, enquanto que, a autonomia dos governos locais gera divergência de políticas (Arretche, 2010). Sendo assim, o recebimento das transferências intergovernamentais em conjunto com o papel regulatório do governo central operam no sentido de promover a equiparação territorial, conforme a autora:

Portanto, em estados federativos que centralizem a formulação de políticas executadas pelas unidades constituintes e que contem com um sistema interjurisdicional de transferências, é possível encontrar redução das desigualdades territoriais. Assim, de acordo com esta teoria, os papéis regulatório e redistributivo do governo central seriam mecanismos necessários para obter cooperação entre jurisdições (ARRETCHE, 2010, p. 593).

As descentralizações das tarefas de execução ocorrem mediante a transferência de recursos seja da Administração Federal para unidades federadas ou para o setor privado. A estrutura descentralizada de governo que as transferências fiscais proporcionam, desenvolve

\footnotetext{
${ }^{5}$ Souza (2003) demonstra indicadores de desigualdade nos municípios brasileiros destacando que as desigualdades não são apenas notadas entre as cinco regiões do país, mas também em uma mesma região ou dentro de um mesmo Estado. Essas diferenças podem ser notadas de acordo com a distribuição da população dos municípios, no Nordeste ocorrem as maiores diferenças onde, o número de pequenos municípios (com população entre 10.000 e 20.000 habitantes) é bastante alto se comparado às demais regiões.
} 
maior conexão entre a arrecadação tributária e as ações públicas, cria maior visibilidade das políticas públicas, fazendo com que a população exija maior eficiência dos governantes no uso dos recursos. As transferências intergovernamentais podem ser discricionárias ou voluntárias, ou seja, que resultam do processo orçamentário dos governos superiores ou decorrentes de determinação constitucional ou legal.

Na análise das transferências fiscais, Gasparini e Miranda (2006) apontam algumas razões para a criação destas transferências, dentre elas estão a adequação entre a capacidade arrecadatória e a necessidade dos gastos públicos diante de suas melhores distribuições entre as esferas de governo, a minimização das diferenças regionais ao longo do território nacional, melhor gerenciamento dos recursos públicos em cada uma das três esferas de governo: União, estados e municípios.

Dentre as principais transferências concedidas pela União aos municípios, destaca-se o Fundo de Participação dos Municípios - FPM, pois esse Fundo representa maior parte das receitas municipais.

O FPM foi criado em 1965 por meio da Emenda Constitucional nำ18, de 1/12/1965, com o objetivo de suplementar o orçamento dos municípios e promover o equilíbrio socioeconômico dos entes federativos. É a principal transferência da União destinada aos municípios. Atualmente o seu montante é constituído de $23,5 \%$ da arrecadação líquida do IR e do IPI. Sua função primordial é reduzir as desigualdades regionais e promover a redistribuição da renda nacional visando o equilíbrio socioeconômico entre os municípios, como dispõe a definição adotada pela Secretaria do Tesouro Nacional:

O rateio da receita proveniente da arrecadação de impostos entre os entes federados representa um mecanismo fundamental para amenizar as desigualdades regionais, na busca incessante de promover o equilíbrio socioeconômico entre Estados e Municípios (MINISTÉRIO DA FAZENDA, 2012).

Segundo Sousa e Arantes (2012), os municípios são os entes federativos com menor capacidade arrecadatória, portanto, necessitam das transferências intergovernamentais:

Sendo os municípios o menor ente da federação, são poucas as competências de arrecadação destes, inviabilizando a sua capacidade de cumprir com suas atribuições. Para compensar esse desequilíbrio há a necessidade do uso de transferências dos entes maiores para os menores. $E$ uma dessas transferências recebidas pelos municípios é o FPM proveniente da União (SOUSA e ARANTES, 2012, v. 2, p. 55).

As transferências do FPM compensam a tendência de concentração dos recursos nas regiões desenvolvidas do país, pois são distribuídas em maior proporção nas regiões menos 
desenvolvidas economicamente (Souza, 2003). Os recursos do FPM são distribuídos em maior parcela aos municípios de menor porte demográfico e são advindos dos impostos sobre a renda (IR) e dos impostos sobre produtos industrializados (IPI) captados em regiões mais industrializadas e de renda familiar mais elevada. Os recursos desta transferência são distribuídos em três partes, da seguinte forma: $10 \%$ são entregues aos municípios que são capitais de estados; $86,4 \%$ aos municípios que não são capitais e 3,6\% fazem parte de uma reserva para suplementar a participação dos municípios mais populosos. Predominantemente, são distribuídos conforme o tamanho do município. A princípio, as parcelas são divididas por estado e depois para cada município (Mendes et al., 2008).

Segundo Bremaeker (2011), a filosofia de distribuição do FPM é de entregar mais recursos, em valores per capita, aos municípios de menor porte demográfico, e para ele, existem dois fatores que justificam essa decisão:

Em primeiro lugar, quanto menor o porte demográfico dos Municípios menor é a sua capacidade de consumo e, portanto, menor é a sua participação na distribuição do ICMS estadual; e, em segundo lugar, quanto menor o porte demográfico dos Municípios menor é a sua arrecadação tributária, não apenas pelo seu menor quantitativo, mas também pelo fato de que os principais tributos municipais têm sua base de tributação no meio urbano (ISS e IPTU) (BREMAEKER, 2011, p. 3).

Sousa e Arantes (2012), destacam o FPM como a principal fonte de receita para muitos municípios, gerando um grau de dependência muito grande em relação a esse repasse. O grau de dependência varia de acordo com o município. Alguns dependem extremamente dessa fonte de recurso enquanto para outros representa apenas uma pequena porcentagem.

Essa dependência está ligada ao tamanho do município, na grande maioria dos casos os municípios menores em relação ao número de habitantes, são os que mais dependem do FPM, como abordam os autores:

No caso dos governos municipais, a alta dependência de receitas de transferências é generalizada. Apenas os municípios mais populosos exibem receitas tributárias e outras receitas correntes um pouco mais significativas. Nos municípios com até 50 mil habitantes, que representam $88 \%$ do total de governos locais, a dependência em relação às transferências supera $80 \%$ da receita total (MENDES et al., 2008, p. 26).

Em síntese, pode-se afirmar, que tal receita é uma transferência constitucional de natureza federal que tem orientação redistributiva e as 
transferências desse Fundo resultaram na redução das desigualdades de receita dos municípios ${ }^{6}$ (Arretche, 2010).

\section{Relações da LRF e das transferências intergovernamentais com as despesas de investimento e pessoal}

No sistema federativo brasileiro existem dois mecanismos que promovem as ações dos orçamentos públicos dos entes municipais: A LRF que determina os parâmetros de controle como limites de endividamento e despesas com pessoal e as transferências intergovernamentais que promovem auxílio financeiro aos entes federativos com baixa capacidade arrecadatória.

Santolin et al. (2009) buscaram identificar os efeitos do aumento da LRF e das transferências sobre as despesas de pessoal e de investimento nos municípios mineiros, onde têm por objetivo mostrar que associado à dependência de recursos que a Constituição acarretou aos municípios, a LRF pode ter promovido alterações sobre a forma de alocação das despesas, os autores assinalam que as decisões de gastos com pessoal e com investimento podem ainda ser utilizadas como indicador de aprovação populacional o que, por sua vez, pode acarretar a permanência ou a troca do partido que detém o poder local nas eleições. Os autores identificaram dois aspectos importantes:

O primeiro é que poucos municípios ultrapassavam os limites de gastos com pessoal em 1995 (antes da vigência da Lei), embora a dispersão fosse muito grande. O segundo aspecto é que a LRF acabou gerando uma menor dispersão desses gastos, vale dizer, paulatinamente todos os municípios foram se enquadrando nos limites impostos pela LRF (SANTOLIN et al., 2009, v. 39, p. 902).

A LRF promove maior transparência devido à obrigatoriedade de prestação de contas e do cumprimento pelos administradores públicos do orçamento realizado. Conforme Santolin et al. (2009), os municípios, em termos agregados, deixam de acumular déficits e passam a apresentar consecutivos superávits. Todavia, apesar destes resultados positivos, a

Lei pode causar distorções no equilíbrio federativo afetando políticas que tenham o objetivo de promover equiparação regional, como é o caso das transferências intergovernamentais, pois, "a rigidez na aplicação dos gastos, principalmente gastos com pessoal, trata igualmente os desiguais" (SANTOLIN et al., 2009, p. 901).

\footnotetext{
${ }^{6}$ Conforme Arretche (2010), a receita do FPM reduz o coeficiente de Gini para em torno de 0,3000. Se os municípios contassem apenas com a arrecadação própria e com as receitas desse fundo, a desigualdade de receita cairia pela metade.
}

Revista de Direito da Cidade, vol. 08, no 1. ISSN 2317-7721 pp.67-92 76 
Desta forma, evidencia-se que a LRF induz os entes federativos a alocarem uma maior parcela dos seus gastos com pessoal e tal fato pode vir acompanhado de redução de gastos com investimento.

Estudos como o de Fioravante et al. (2006) registram que a limitação de despesas com pessoal em $60 \%$ estimulou o aumento desse gasto na maioria dos entes federativos que apresentavam despesas inferiores a esse teto.

Ainda, de acordo com Santolin et al. (2009) há um crescimento das despesas com pessoal bastante superior aos gastos com investimentos:

O crescimento receita orçamentária, a partir de 1998, foi da ordem de $47 \%$ em termos reais. Ao todo, a receita tributária apresentou um crescimento total de $20 \%$ enquanto as receitas de transferências se expandiram em $78 \%$. Por sua vez, as despesas com pessoal cresceram $98,5 \%$ e os gastos de investimento 21,5\% (SANTOLIN et al., 2009, v.39, p. 907).

Tal fato, segundo os autores, decorre do aumento das transferências intergovernamentais, o que levou ao aumento de autonomia e responsabilidades dos municípios dentro da federação brasileira.

A maneira como são alocadas as despesas com investimento e pessoal pode ocasionar notáveis efeitos nas conjunturas municipais, sendo que, os decisores governamentais, por meio destas despesas, podem intervir afetando a forma que estes gastos incidem sobre a economia. No entanto, pressupõe-se que os atores políticos - por meio de regras, no caso deste estudo a LRF são induzidos a realizar uma determinada alocação de despesas que prioriza a rubrica gasto com pessoal, acarretando um padrão de comportamento dos governos locais, no sentido que:

Instituições são padrões regularizados de interação que são conhecidos, praticados e aceitos regularmente (embora não necessariamente aprovados normativamente) por agentes sociais dados, que, em virtude dessas características, esperam continuar interagindo sob as regras e normas incorporadas (formal ou informalmente) nesses padrões (O'DONNELL, 1991, p. 27).

O que significa dizer também que os atores políticos agem em conformidade com o cálculo racional diante de opções que estimulam a maximização do seu payoff, ou seja, a retribuição que recebe de acordo com sua escolha. Isto é o que Tsebelis chama de pressuposto da racionalidade indicando que "os atores individuais e institucionais tentam promover ao máximo a realização de seus objetivos" (TSEBELIS, 1998, p. 21).

Diante desta discussão sobre LRF e FPM, este artigo tem como hipótese que as regras fiscais e de transferência de recursos incentivam uma mudança na alocação do gasto com investimento em detrimento do gasto com pessoal. 


\section{METODOLOGIA}

Utiliza-se métodos quantitativos para atender aos fins da presente pesquisa. Segundo Silva e Menezes (2005), na técnica de pesquisa quantitativa pode-se traduzir informações em números a fim de classificá-los e analisá-los por meio de recursos e técnicas estatísticas como percentagem, média, moda, mediana, desvio-padrão, coeficiente de correlação, análise de regressão, etc. A técnica estatística empregada neste estudo é a construção de um modelo econométrico de regressão com dados em painel.

De um modo geral, o modelo de regressão permite estudar a relação entre uma variável dependente e suas variáveis independentes, estas são associadas linearmente e representadas por um modelo matemático que se denomina modelo de regressão linear. Assim, após a seleção das variáveis foi construído o modelo a fim de mensurar o efeito das variáveis independentes ou explicativas na variável dependente.

\section{Método de estimação}

A regressão com dados em painel foi calculada por meio do software Eviews 7.1.

A respeito da estrutura de dados, há uma variedade de tipos. Segundo Gujarati (2011), uma pesquisa é caracterizada por apresentar dados de corte transversal (cross-section), dados de séries temporais e dados em painel (longitudinais). Um conjunto de dados de corte transversal descreve eventos em um determinado ponto no tempo, os dados de séries temporais consistem em observações de eventos ao longo do tempo e um conjunto de dados em painel combina séries temporais e informações em corte transversal, ou seja, compõe uma série temporal para cada registro do corte transversal do conjunto de dados. Utiliza-se a análise de dados em painel, uma vez que a mesma unidade de corte transversal (os municípios, no caso deste trabalho) é acompanhada ao longo do tempo. Em resumo, "os dados em painel têm uma dimensão espacial e outro temporal" (GUJARATI, 2011, p. 587).

No caso desta pesquisa, utilizou-se uma base de dados composta por um painel balanceado dos municípios paranaenses em sete anos (2002, 2005, 2007, 2008, 2009, 2010 e 2011). O painel denomina-se balanceado, pois para cada município da amostra tem-se o mesmo número de dados temporais. Wooldridge (2001) ressalta que com a aplicação de dados em painel, por unir essas duas características (dados em corte transversal e dados em séries de tempo), faz-se 
possível observar a heterogeneidade dos indivíduos, há maior nível de informação a respeito das variáveis explicativas.

Acrescenta-se ainda como benefícios que a utilização de dados em painel proporciona algumas vantagens sobre dados de corte transversais ou de séries temporais, como destaca Gujarati (2011), as principais vantagens são: a análise torna-se mais enriquecida e eficiente, pois, combinando séries temporais com observações de corte transversal, os dados em painel oferecem dados com maior variabilidade, menos colinearidade entre as variáveis, dados mais informativos e mais graus de liberdade e como aumentam consideravelmente o tamanho da amostra ao estudar observações de corte transversal repetidas, os dados em painel nos permitem estudar modelos comportamentais mais complicados. Isto fortalece a eficiência da estimação do modelo em painel, permitindo identificar e medir efeitos que as análises puramente seccionais ou temporais não permitem.

Entretanto, embora exista um número de vantagens considerável, Gujarati (2011) menciona que a modelagem com dados em painel gera problemas de estimação e inferência, sendo comum, nesse tipo de abordagem a existência de heterocedasticidade e autocorrelação.

A expressão matemática para o modelo pode ser representada como uma equação linear na forma:

$$
Y_{i t}=\beta_{0}+\beta_{1} X_{1 i t}+\beta_{2} X_{2 i t}+\beta_{3} X_{3 i t}+W_{i t} \quad i=1, \ldots, 321 ; t=2002, \ldots, 2011
$$

Em que i representa a i-ésima unidade do corte transversal e t o t-ésimo período de tempo. Y é a variável dependente das variáveis independentes (explicativas) X's. $\beta_{0}$ é a constante do modelo, $\beta_{1}, \beta_{2}$ e $\beta_{3}$ são parâmetros que serão determinados a partir dos dados observados e $W_{\text {it }}$ é termo de erro da regressão, que contém fatores não observados. 


\section{Definição do modelo econométrico e das variáveis}

O modelo econométrico de regressão apresentado neste artigo, tem o objetivo de identificar os efeitos da LRF na alocação do gasto com investimento em detrimento do gasto com pessoal, bem como, das demais variáveis que influenciam na alocação de tais despesas. Diante disso, foi adotado o seguinte modelo:

$$
I N V_{i t}=\beta_{0}+\beta 1_{i t} I P D M+\beta_{2 i t} D E P+\beta_{3 i t} A M O R T(-1)+W_{i t}
$$

Onde, i: 1,..,321 representa os municípios paranaenses; t: 2002,..2011 representa o período de tempo analisado. Pelo modelo apresentado, o termo de erro $W_{\text {it }}$ é composto, consistindo de dois elementos: $\varepsilon i$, que é o elemento de corte transversal, e $u_{i t}$ que é o elemento combinado da série temporal e do corte transversal (GUJARATI, 2011). A alocação dos gastos com investimento em detrimento dos gastos com pessoal (INV) é a variável dependente que será explicada a partir dos efeitos das variáveis independentes ou explicativas: Índice IPARDES de Desempenho Municipal (IPDM), grau de dependência dos orçamentos municipais em relação ao FPM (DEP) e a soma das amortizações com o pagamento dos juros da dívida pública em relação à receita corrente líquida (AMORT).

A variável dependente INV se refere a quanto os municípios estão gastando com investimento em detrimento do gasto com pessoal. Ela representa uma medida de alocação do gasto público, sob o pressuposto de que uma maior parcela de gastos com pessoal acarreta uma consequente redução de despesas com investimento. Consiste na divisão entre as duas despesas, como segue:

$$
I N V=\frac{\text { Gasto com Investimento }}{\text { Gasto com Pessoal }}
$$

O IPDM (Índice IPARDES de Desempenho Municipal) é uma variável independente utilizada como proxy do desenvolvimento dos municípios. Este índice mede o desempenho da gestão e ações públicas dos 399 municípios do Estado do Paraná, considerando três dimensões: renda, emprego e agropecuária, saúde e educação. Ele varia de 0 a 1 apresentando, respectivamente, condições mínimas e máxima de desenvolvimento. Sua elaboração é feita pelo Instituto Paranaense de Desenvolvimento Econômico e Social e baseia-se em diferentes estatísticas de natureza administrativa disponibilizadas pelas entidades públicas. 
A variável independente DEP representa o grau de dependência dos orçamentos municipais em relação ao FPM. Esta razão de dependência é calculada da seguinte maneira:

\begin{tabular}{|l|r|}
\hline \multirow{2}{*}{$\mathrm{DEP}=$} & Fundo de Participação dos Municípios \\
\cline { 2 - 2 } & Receita Corrente Líquida \\
\hline
\end{tabular}

Por fim, a variável independente AMORT mede o quanto os municípios estão amortizando da dívida pública em relação à receita corrente líquida, captando os efeitos da LRF sobre a alocação dos gastos municipais. Considera-se nesta variável a defasagem de um ano (-1), ou seja, mede-se o impacto no período antecedente, pois a amortização da dívida que interfere no orçamento presente da administração pública é a que foi efetuada no período anterior. É calculada como segue:

\begin{tabular}{|c|c|}
\hline \multirow{2}{*}{ AMORT $=$} & Amortização + pagamento de juros da dívida pública \\
\cline { 2 - 2 } & Receita Corrente Líquida \\
\hline
\end{tabular}

A princípio, a intenção era inserir no modelo a variável estoque da dívida pública a fim de medir, via esse parâmetro os efeitos da LRF, no entanto, dada a limitação de dados existentes para essa variável fez com que, ao eliminar da amostra todos os municípios com esse dado zerado em algum ano, restassem apenas 22 municípios para as análises. Diante disso, ficaria difícil de captar a heterogeneidade existente no Estado paranaense, bem como, comprometeria o modelo. Sendo assim, optou-se por utilizar a variável amortização da dívida a fim de captar os impactos da LRF sob a tomada de decisão entre gasto com investimento/gasto com pessoal.

Neste caso, o modelo de regressão que está sendo adotado é de efeitos aleatórios, pois para fins deste estudo, essa foi a abordagem que se apresentou mais adequada, fato que será descrito e analisado na apresentação dos resultados.

Assim, o modelo deve avaliar a seguinte hipótese: A LRF está produzindo uma mudança na alocação do gasto com investimento em detrimento do gasto com pessoal?

\section{Base de dados}

A delimitação da pesquisa ocorreu após a coleta de dados, onde, do universo de 399 municípios paranaenses foram utilizados os que possuem informações disponibilizadas para todos os anos do estudo. O total de municípios com informações disponíveis nos bancos de dados são 
321. Sendo assim, foi utilizada uma amostra de $321^{7}$ municípios do Estado do Paraná entre os anos de 2002 a 2011, ou seja, o período pós-implementação da LRF e foram obtidos na Secretaria do Tesouro nacional (STN-FINBRA) e no Instituto Paranaense de Desenvolvimento Econômico e Social (IPARDES).

Em virtude da disponibilidade de informações para a variável IPDM, os dados serão capturados e analisados para os anos de 2002, 2005, 2007, 2008, 2009, 2010 e 2011.

\section{Análise dos resultados}

A partir da estimação do modelo de regressão, obteve-se os resultados apresentados a seguir. Inicialmente, foi realizada a identificação da abordagem mais adequada para os fins desta pesquisa: efeitos fixos ou efeitos aleatórios. Foi empregado o teste de Hausman para a decisão do modelo mais apropriado, sob a hipótese nula tanto o modelo de efeitos fixos quanto o de efeitos aleatórios são consistentes, sendo que o segundo é mais eficiente. Sob a hipótese alternativa, o modelo de efeitos aleatórios fornece estimativa inconsistente dos parâmetros e, desta forma, a diferença entre os dois estimadores deve ser diferente de zero.

As pressuposições que se fazem com base na provável correlação entre os regressores $X$ e o componente de erro individual definem a escolha entre modelos de efeitos fixos ou aleatórios. Se houver correlação o modelo de efeitos fixos é o mais indicado, se não houver, o de efeitos aleatórios. (GUJARATI, 2011).

Sendo assim, ao rejeitar a hipótese nula de que não há correlação entre os erros, considera-se o modelo de efeitos fixos mais eficiente, caso contrário, na ausência de correlação, o modelo indicado é o de efeitos aleatórios. A tabela 1 apresenta o resultado do teste.

\footnotetext{
${ }^{7}$ Destaca-se que esta amostra mantém a heterogeneidade que caracteriza o Paraná.
} 
Tabela 1 - Resultado do teste de Hausman

\begin{tabular}{|c|c|c|c|c|}
\hline \multicolumn{5}{|c|}{ Efeitos Aleatórios Correlacionados - Teste de Hausman } \\
\hline \multicolumn{5}{|c|}{ Teste de efeitos aleatórios nos cortes transversais } \\
\hline \multicolumn{2}{|c|}{ Resumo do Teste } & $\begin{array}{l}\text { Estatística } \\
\text { Qui-Quad. }\end{array}$ & $\begin{array}{l}\text { Graus de } \\
\text { Liberdade }\end{array}$ & Prob. \\
\hline \multicolumn{2}{|c|}{ Efeitos Aleatórios } & 0,000000 & 3 & 1,0000 \\
\hline \multicolumn{5}{|c|}{ Testes de comparação de efeitos aleatórios nos cortes transversais: } \\
\hline Variável & $\begin{array}{c}\text { Efeitos } \\
\text { Fixos }\end{array}$ & $\begin{array}{c}\text { Efeitos } \\
\text { Aleatórios }\end{array}$ & Var (Dif.) & Prob. \\
\hline IPDM & $-1,324046$ & $-1,324046$ & 0,000000 & 1,0000 \\
\hline DEP & 1,042191 & 1,042191 & 0,000000 & NA \\
\hline AMORT (-1) & $-8,305512$ & $-8,305512$ & 0,000000 & 1,0000 \\
\hline
\end{tabular}

Fonte: Eviews; Elaboração dos autores.

O estimador de efeitos aleatórios não é significantemente diferente do estimador de efeitos fixos, uma vez que o teste não é rejeitado nem mesmo aos níveis críticos mais elevados ${ }^{8}$, quando há falha em rejeitar a hipótese nula significa que os efeitos fixos e aleatórios são similares e as estimativas de efeitos fixos são imprecisas, desse modo, pela estatística do teste de Hausman, a abordagem de efeitos aleatórios é mais apropriada.

Frente a isso, foi estimado o modelo de regressão sob efeitos aleatórios, onde os gastos com investimento em relação aos gastos com pessoal (INV) aparece como variável dependente tendo como suas variáveis explicativas a proxy de desenvolvimento municipal (IPDM), grau de dependência das transferências (DEP) e a amortização mais os juros da dívida pública em relação a RCL (AMORT).

É importante ressaltar que a variável AMORT foi calculada considerando 1 ano de defasagem, pois, o orçamento municipal é realizado levando em conta o ocorrido no período anterior. Em outras palavras, a amortização da dívida que interfere no orçamento presente da administração pública é a que foi efetuada no período antecedente. Num primeiro momento, nas tentativas de montagem do modelo, a regressão foi realizada sem levar em consideração a defasagem dessa variável, o que resultou em um R-quadrado pouco significativo. Abaixo, na tabela 2 são apresentados os resultados da regressão sobre efeitos aleatórios sem a defasagem na variável AMORT, na tabela 3 apresenta-se os resultados considerando um ano de defasagem na variável AMORT. Este último foi o modelo escolhido, pois aumentou significativamente o Rquadrado, bem como, resultou sinais coerentes e esperados aos coeficientes. O teste de Hausman

\footnotetext{
${ }^{8} \mathrm{O}$ teste de Hausman não rejeita a hipótese de que o estimador de efeitos aleatórios é adequado ao nível de significância de $10 \%$.
} 
não rejeita a hipótese de que o estimador de efeitos aleatórios é adequado ao nível de significância de $10 \%$.

Tabela 2 - Resultados da regressão com efeitos aleatórios sem a defasagem na variável AMORT

\begin{tabular}{|c|c|c|c|c|}
\hline \multicolumn{5}{|c|}{ Variável Dependente: INV } \\
\hline \multicolumn{4}{|c|}{ Pétodo: Mínimos Quadrados em Painel } \\
\hline \multicolumn{4}{|c|}{ Cortes transversais incluídos: 321} \\
\hline Observações totais do painel (balanceado): 2247 \\
\hline Variável & Coeficiente & Erro Padrão & Estatística-t & P-valor \\
\hline IPDM & $-2,016863$ & 0,048820 & $-41,312330$ & 0,0000 \\
\hline DEP & $-9,498021$ & 0,210531 & $-45,114570$ & 0,0000 \\
\hline AMORT & 25,254640 & 0,540401 & 46,733150 & 0,0000 \\
\hline C & 4,156886 & 0,091320 & 45,519840 & 0,0000 \\
\hline R-quadrado & 0,539678 & Média Var. Dep. & 0,136303 \\
\hline R-quadrado ajustado & 0,539062 & Erro Padrão Var.Dep. & 0,085356 \\
\hline Estatística-F & 876,5575 & Soma quad Resíduos & 7,532505 \\
\hline Prob. (Estatística-F) & 0,000000 & Estatística Durbin-Watson & 1,792414 \\
\hline
\end{tabular}

Fonte: Eviews; Elaboração dos autores.

Tabela 3 - Resultados da regressão com efeitos aleatórios considerando defasagem de um ano na variável AMORT

Variável Dependente: INV

Método: Mínimos Quadrados em Painel

Períodos incluídos: 6

Cortes transversais incluídos: 321

Observações totais do painel (balanceado): 1926

\begin{tabular}{|c|c|c|c|c|}
\hline \multicolumn{5}{|c|}{ Observações totais do painel (balanceado): 1926} \\
\hline Variável & Coeficiente & Erro Padrão & Estatística-t & P-valor \\
\hline IPDM & $-1,324046$ & 0,011585 & $-114,2871$ & 0,0000 \\
\hline DEP & 1,042191 & 0,029706 & 35,08334 & 0,0000 \\
\hline AMORT (-1) & $-8,305512$ & 0,046519 & $-178,5404$ & 0,0000 \\
\hline C & 0,749419 & 0,013894 & 53,93718 & 0,0000 \\
\hline Especificação do Efeito Aleatório & & & \\
\hline R-quadrado & 0,952560 & Média Var. Dep. & 0,130565 \\
\hline R-quadrado ajustado & 0,952486 & Erro Padrão Var.Dep. & 0,090939 \\
\hline Estatística-F & 12864,20 & Soma quad Resíduos & 0,755219 \\
\hline
\end{tabular}




\section{\begin{tabular}{l|l|l|l|}
\hline Prob(Estatística-F) & 0,000000 & Estatística Durbin-Watson & 2,135442
\end{tabular}}

Fonte: Eviews; Elaboração dos autores.

Antes das análises, a título de comparação, são apresentados os resultados sobre a abordagem de efeitos fixos. Cabe ressaltar que os resultados frente ambas estimações foram bastante similares.

Tabela 4 - Resultados da regressão com efeitos fixos

\begin{tabular}{|c|c|c|c|c|}
\hline \multicolumn{5}{|c|}{ Variável Dependente: INV } \\
\hline \multicolumn{5}{|c|}{ Períodos incluídos: 6} \\
\hline \multicolumn{4}{|c|}{ Cortes transversais incluídos: 321} \\
\hline \multicolumn{4}{|c|}{ Observações totais do painel (balanceado): 1926 } \\
\hline Variável & Coeficiente & Erro Padrão & Estatística-t & P-valor \\
\hline IPDM & $-1,324046$ & 0,011585 & $-114,2871$ & 0,0000 \\
\hline DEP & 1,042191 & 0,029706 & 35,08334 & 0,0000 \\
\hline AMORT (-1) & $-8,305512$ & 0,046519 & $-178,5404$ & 0,0000 \\
\hline C & 0,749419 & 0,013894 & 53,93718 & 0,0000 \\
\hline Cortes Transversais Fixos & & & \\
\hline R-quadrado & 0,952560 & Média var. dep. & 0,130565 \\
\hline R-quadrado ajustado & 0,942995 & Erro padrão var. dep. & 0,090939 \\
\hline Erro Padrão da regressão & 0,021712 & Critério de Akaike & $-4,669623$ \\
\hline Soma Quad. Resíduos & 0,755219 & Critério de Schwarz & $-3,733758$ \\
\hline Log verossim. & 4820,847 & Critério de Hannan-Quinn & $-4,325337$ \\
\hline Estatística-F & 99,58887 & Estatística Durbin-Watson & 2,135442 \\
\hline Prob. (Estatística-F) & 0,000000 & \\
\hline
\end{tabular}

Verifica-se pelos resultados apresentados na tabela 3 que a regressão como um todo se mostrou significativa, pela estatística constata-se que todos os parâmetros (IPDM, DEP e AMORT) mostraram-se significativos a $1 \%$ de probabilidade e os sinais foram coerentes com as expectativas.

Ademais, constata-se pela análise do R-quadrado ajustado, que o poder de explicação do modelo é de 95\%. Pode-se afirmar assim, que o conjunto de variáveis independentes: IPDM, grau de dependência e amortização da dívida, explicam aproximadamente $95 \%$ da variação da relação gastos com Investimento e gastos com pessoal.

Com o teste de Durbin-Watson, foi analisada a ausência de auto correlação entre os resíduos, que segundo Gujarati (2011) é o teste mais aplicado para este fim. Examinando a estatística de Durbin-Watson presente na tabela 3 verifica-se que o referido coeficiente é muito próximo a 2,0000 indicando que a hipótese nula de correlação entre os resíduos igual a zero pode ser aceita, não havendo assim, evidência de auto correlação entre os resíduos. 
A primeira variável explicativa é o IPDM a qual se refere ao nível de desenvolvimento dos municípios paranaenses, observa-se que ela produz um impacto negativo sobre a variável dependente. Sendo assim, o aumento de $1 \%$ no nível de desenvolvimento gera uma redução na variável dependente, em outras palavras, essa variável explicativa contribui para a probabilidade de os municípios reduzirem a alocação dos gastos com investimentos/gastos com pessoal. É razoável esperar que o sinal desse coeficiente seja negativo, uma vez que, quanto maior o padrão de desenvolvimento do ente federativo maior é a sua demanda por gastos com pessoal, que reúne despesas com salários, assistência social, previdência social e treinamento.

O resultado de -1,32 para o parâmetro IPDM não representa a elasticidade pontual, para o cálculo da elasticidade deste coeficiente foi utilizado uma forma funcional. Conforme Hill (2010), o modelo que é linear nas variáveis descreve o ajustamento de uma reta aos dados originais, com coeficiente angular $\beta_{2}$ e elasticidade pontual $\beta_{2} X_{t} / Y_{t}$. O coeficiente angular da relação é constante, mas a elasticidade varia em cada ponto, sendo assim, a partir da fórmula descrita abaixo é calculado e apresentado na tabela 5 a elasticidade deste coeficiente variando de acordo com os diferentes padrões de desenvolvimento.

Dado que:

$$
\begin{gathered}
\beta_{2}=-1,32 \\
X_{t}=\text { IPDM } \\
Y_{t}=\text { Inv } / \text { Pes }
\end{gathered}
$$

Quadro 1 - Cálculo da elasticidade pontual para diferentes padrões de desenvolvimento

\begin{tabular}{|c|c|c|}
\hline IPDMX & Inv/Pes $Y_{t}$ & $\begin{array}{c}\text { Elasticidade } \\
\beta_{2} X_{t} / Y_{t}\end{array}$ \\
\hline 0,3 & 0,1 & $-3,96$ \\
\hline & 0,5 & $-0,79$ \\
\hline & 1 & $-0,40$ \\
\hline & 1,5 & $-0,26$ \\
\hline 0,4 & 0,1 & $-5,28$ \\
\hline & 0,5 & $-1,06$ \\
\hline & 1 & $-0,53$ \\
\hline & 1,5 & $-0,35$ \\
\hline 0,5 & 0,1 & $-6,60$ \\
\hline & 0,5 & $-1,32$ \\
\hline & 1 & $-0,66$ \\
\hline & 1,5 & $-0,44$ \\
\hline 0,6 & 0,1 & $-7,92$ \\
\hline & 0,5 & $-1,58$ \\
\hline
\end{tabular}




\begin{tabular}{|c|c|c|}
\hline & 1 & $-0,79$ \\
\hline & 1,5 & $-0,53$ \\
\hline 0,7 & 0,1 & $-9,24$ \\
\hline & 0,5 & $-1,85$ \\
\hline & 1 & $-0,92$ \\
\hline & 1,5 & $-0,62$ \\
\hline 0,8 & 0,1 & $-10,56$ \\
\hline & 0,5 & $-2,11$ \\
\hline & 1 & $-1,06$ \\
\hline & 1,5 & $-0,70$ \\
\hline
\end{tabular}

Fonte: Elaboração dos autores.

À luz destes dados, constata-se que os municípios com maior padrão de desenvolvimento, os outliers nas análises, apresentam uma elasticidade do parâmetro IPDM relativamente menor se comparados ao demais municípios paranaenses. Possivelmente isso ocorre em virtude da maior demanda destes entes federativos, por gastos com pessoal. É natural que municípios maiores e mais desenvolvidos demandem maior quantidade de serviço público, fazendo que a alocação de gastos com investimento em detrimento dos gastos com pessoal seja reduzida a uma elasticidade cada vez menor. Ao realizar uma análise mais desagregada, verifica-se que os municípios com padrão de desenvolvimento menor, por exemplo, 0,3 apresentam elasticidade variando de -3,96 a 0,26 , enquanto que os municípios com padrão de desenvolvimento igual a 0,8 denotam elasticidade de $-10,56$ a -0,70, evidenciando assim, a redução a uma elasticidade cada vez menor aos municípios com IPDM elevado.

A segunda variável explicativa é a DEP, que indica o impacto que se tem na variável explicada advindo do grau de dependência dos orçamentos municipais em relação às transferências. Verificou-se a partir de sua análise, uma relação positiva com a variável dependente, onde com o aumento de $1 \%$ do grau de dependência, a alocação investimento/pessoal aumenta em 1,04. Sendo assim, recursos advindos das transferências intergovernamentais contribuem positivamente na alocação dos gastos com investimentos em detrimento dos gastos com pessoal evidenciando que a dependência das transferências é um fator que corrobora com uma melhor alocação dos gastos com investimentos dos entes federativos.

É preciso ter cautela com a estaticidade que ocorre ao observarmos a relação IPDM com grau de dependência apresentados nos gráficos de dispersão na seção anterior, onde presumimos a ineficiência do canal das transferências, pois, ao observar a regressão fica evidente, a partir da análise da variável explicativa DEP, que tem-se uma melhor alocação investimento/pessoal na 
medida em que há aumento do grau de dependência, inferindo assim, que o maior repasse das transferências aos entes federativos contribui para que estes aloquem seus gastos com investimento corroborando com o desenvolvimento municipal.

A variável amortização, por sua vez, apresentou elasticidade -8,30 causando um impacto negativo na variável explicada. Quando há aumento da amortização da dívida, há uma menor alocação entre gasto com investimento/gasto com pessoal. Embora tenhamos um resultado positivo do parâmetro DEP, este não compensa o efeito negativo causado pela amortização e pagamento dos juros da dívida pública, assim, infere-se que as transferências conseguem exercer influência positiva na alocação investimento/pessoal, todavia o ajuste fiscal via manutenção de uma solvência fiscal através da amortização e pagamento dos juros na tentativa de manter o estoque da dívida mais estável, impacta negativamente na alocação do gasto público.

De modo geral, no tocante à magnitude dos três parâmetros explicativos do modelo de regressão, infere-se que a LRF pode estar produzindo tentativas por parte da gestão pública, de atribuir maior ênfase nas despesas com pessoal defronte as despesas com investimento, pois notase que a contribuição positiva da variável DEP, é baixa se comparada ao efeito desfavorável causado pelo parâmetro AMORT - que é a variável utilizada para medir o impacto da LRF - e do parâmetro IPDM ${ }^{9}$. Evidencia-se assim, que o impacto negativo destes últimos anula o estímulo na melhor alocação das despesas com investimentos em relação às despesas com pessoal gerado pelas transferências.

Aqui cabe também destacar que a teoria da escolha racional, segundo Baert (1997), visa explicar padrões de comportamento de um determinado grupo de agentes no âmbito social e político, levando em conta que estes agem racionalmente. Bem como, cabe destacar a premissa de Downs (1957) que assume que a ação política seja racional, com os políticos, bem como eleitores, agindo de acordo com seu interesse, tendo os políticos como objetivo maximizar aprovação populacional de modo a se manter no poder e os eleitores objetivando aumentar os benefícios obtidos da atividade fiscal, votando naqueles que melhor satisfaçam seus interesses.

Infere-se que, após a implementação da LRF, os entes federativos foram submetidos a uma disciplina fiscal, e os resultados para os municípios paranaenses decorrentes dessa nova configuração institucional indicam que a imposição do limite de 60\% das despesas com pessoal estimulou os municípios paranaenses, que antes apresentavam gastos inferiores ao teto

\footnotetext{
${ }^{9}$ O impacto do IPDM chega a -10,56 em municípios com maior padrão de desenvolvimento, esse número chega a superar o impacto causado pelo parâmetro AMORT que é de -8,30.
} 
determinado, a utilizarem uma manobra de gestão orçamentária para fazer frente aos limites da LRF, causando aumentos nos gastos com pessoal, o que prejudica a rubrica investimento que não possui enquadramento tão rígido junto à LRF.

Portanto, o resultado apresentado pode ser interpretado à luz do pressuposto da racionalidade no sentido do desestímulo à produção de bens públicos gerando resultados subótimos.

\section{CONCLUSÃO}

O objetivo do artigo foi realizar um estudo dos efeitos da Lei de Responsabilidade Fiscal e das transferências intergovernamentais, representadas pelo FPM, na alocação dos gastos com investimento em detrimento dos gastos com pessoal nos municípios paranaenses por meio da estimação de um modelo econométrico de dados em painel. Para tanto, foi analisado o período posterior a implementação da LRF.

Inicialmente, a partir dos resultados encontrados na análise da regressão econométrica, depreende-se que a nova configuração institucional imposta pela LRF pode estar produzindo tentativas, por parte dos decisores governamentais, de aplicar maior ênfase às despesas com pessoal. Isso visualiza-se na comparação dos três parâmetros estimados, onde a variável que mede o impacto da LRF (AMORT) produz um efeito negativo na alocação das despesas que supera o efeito benéfico causado pela dependência do FPM.

A conclusão desta sequência de fatos é que as transferências estão impulsionando gastos com investimentos, fator que influencia positivamente no desenvolvimento econômico dos municípios; entretanto, esse efeito se anula, pois, é baixo se comparado aos impactos contrários da amortização da dívida e do IPDM.

Contudo, salienta-se a relevância da Lei de Responsabilidade Fiscal como ferramenta de estímulo à transparência e fiscalização da conduta do gestor público ao acrescentar mecanismos de controle das finanças públicas. Ressalta-se que após sua implementação os municípios se enquadram aos limites impostos pela Lei.

No entanto, há um processo de equalização dos gastos de pessoal pós promulgação da LRF que induz os municípios - por meio de seus atores políticos - a apresentarem um comportamento padrão ampliando seus gastos com pessoal, mesmo aqueles que apresentavam uma despesa bastante inferior ao teto. Esse fato decorre de que os atores envolvidos no processo político atuam visando seus interesses particulares. Diante do pressuposto da racionalidade, os decisores 
governamentais agem de acordo ao estímulo do seu payoff, desestimulando-os de se dedicar a produção de bens públicos levando a ocorrência de resultados subótimos. Assim, gastos com pessoal são estimulados, uma vez que podem maximizar a aprovação populacional. Nos pequenos municípios principalmente, onde há baixa geração de renda, as despesas com folhas de salário servem aos interesses clientelistas, estes gastos garantem renda mínima a parte da população, sendo o município o principal empregador local. Possibilitando desta forma, aos governantes, um bom desempenho eleitoral e manutenção do poder político. Este cenário incide sobre as despesas com investimento, ocasionando uma consequente redução do mesmo, isso ocorre provavelmente, devido a não existência de um enquadramento tão rígido quanto aos investimentos junto a LRF.

Os resultados sugerem que há um comportamento cíclico provavelmente relacionado com o período de eleições municipais, uma vez que, os sinais dos parâmetros para a variável AMORT diferem quando se utiliza contemporaneamente em detrimento ao uso defasado num período anterior. Diante disso, uma importante análise futura, concerne em realizar um estudo mais detalhado visando desenvolver uma análise econométrica que capture os efeitos dos ciclos políticos eleitorais.

\section{REFERÊNCIAS BIBLIOGRÁFICAS}

ARAUJO, Wilson José. MORAES, Tiago Cacique. A Lei de Responsabilidade Fiscal (LRF): balanço preliminar e impactos sobre governos municipais. Anais do XXVII Encontro da ANPAD, 24 a 27 de setembro, Atibaia, 2003.

ARRETCHE, Marta. Estado federativo e políticas sociais: determinantes da descentralização. Rio de Janeiro: Revan, 2000.

Federalismo e igualdade territorial: uma contradição em termos? Revista Dados. Rio de Janeiro, Vol. 53 n.3 p. 587-620, 2010.

Relações federativas nas políticas sociais. EDUC. SOC. Campinas, Vol. 23, n. 80, p.25-48, 2002.

BAERT, Patrick. Algumas limitações das explicações da escolha racional na Ciência Política e na Sociologia. Revista Brasileira de Ciências Sociais, São Paulo, v. 12, n. 35, p. 63-47, 1997.

BRASIL. Lei Complementar no 101, de 4 de maio de 2000. Estabelece normas de finanças públicas voltadas para a responsabilidade na gestão fiscal e dá outras previdências. Diário Oficial da União. Poder Executivo, Brasília, 5 de maio de 2000.

BREMAEKER, F. E. J. Reforma Tributária: Vantagem ou Desvantagem para os Municípios. Transparência Municipal. Salvador, 2011.2 Disponível em: <www.oim.tmunicipal.org.br/abre_documento.cfm?pdf...> Acesso em: 14/06/2015.

DOWNS, A. An economic theory of democracy. Nova York, Harper, 1957. 
FIORAVANTE, D. G.; PINHEIRO, M. M. S.; VIEIRA, R. S. V.; SANTOS, J. C. Lei de responsabilidade fiscal e finanças públicas municipais: impactos sobre despesas com pessoal e endividamento. IPEA, Rio de Janeiro, Texto n. 1223, 2006.

GASPARINI, C. E.; MIRANDA, R. B. Evolução dos Aspectos Legais e dos Montantes de Transferências Realizadas pelo Fundo de Participação dos Municípios. IPEA, Brasília. Texto n. 1243, 2006.

GERIGK, W. O impacto da lei de responsabilidade fiscal sobre a gestão financeira dos pequenos municípios do Paraná. 315 p. Dissertação (Mestrado em Contabilidade) - Universidade Federal do Paraná, Curitiba, 2008.

GUJARATI, D.; PORTER, D. C. Econometria Básica. 5o ed. Rio de Janeiro: Elsevier, 2011.

HILL, C.; GRIFFITHS, W.; JUDGE, G. Econometria. São Paulo: Saraiva, 1999.

MENDES, M.; MIRANDA, R. B.; COSIO, F. B. Transferências Intergovernamentais no Brasil: diagnóstico e proposta de reforma. Consultoria Legislativa do Senado Federal, Brasília, Texto n. 40, 2008.

MINISTÉRIO DA FAZENDA - SECRETARIA DO TESOURO NACIONAL. O que você precisa saber sobre as transferências constitucionais e legais - Fundo de Participação dos Municípios. Brasília, 2012. Disponível

em: http://www3.tesouro.fazenda.gov.br/estados_municipios/download/CartilhaFPM.pdf. Acesso em: 15 mar. 2015.

NORTH, D. Institutions, Institutional Change, and Economic Performance. Nova lorque, Cambridge University Press, 1990.

O ’DONNELL, G. “Democracia Delegativa?” Novos Estudos CEBRAP, São Paulo, 31, 1991.

SANTOLIN, R.; JAYME JR. F. G.; REIS, J. C. Lei de responsabilidade fiscal e implicações na despesa de pessoal e de investimento nos municípios mineiros: um estudo com dados em painel dinâmico. Revista de Estudos Econômicos, São Paulo, v. 39, pp. 895-923, 2009.

SILVA, E.; MENEZES, E. Metodologia da Pesquisa e Elaboração de Dissertação, Florianópolis: Laboratório de Ensino a Distância da UFSC, 2005.

SOUSA, A. L. R.; ARANTES, E. C. FPM: Importância, dependência e o impacto das reduções para o município de Boa Vista-RR - Uma análise do período de 2001 a 2011. Revista de Administração de Roraima. Boa Vista, Ed 2, Vol2, pp. 51 - 69, 2ㅇ Sem., 2012.

SOUZA, C. Federalismo e Conflitos Distributivos: Disputa dos Estados por Recursos Orçamentários Federais. Revista Dados. Rio de Janeiro, vol.46, no 2, 2003.

TSEBELIS, G. Jogos ocultos: escolha racional no campo da política comparada. São Paulo: Edusp, 1998. 
VELOSO, G. O.; TEIXEIRA, A. M. A Lei de Responsabilidade Fiscal e as microrregiões do Estado do Rio Grande do Sul: uma análise empírica. Ensaios FEE, Porto Alegre, v. 28, n. 2, pp. 443-470, 2007.

WOOLDRIDGE, J. M. Econometric analysis of cross section and panel data. MIT Press, Cambridge MA, 2002.

Trabalho enviado em 22 de setembro de 2015.

Aceito em 20 de janeiro de 2016. 